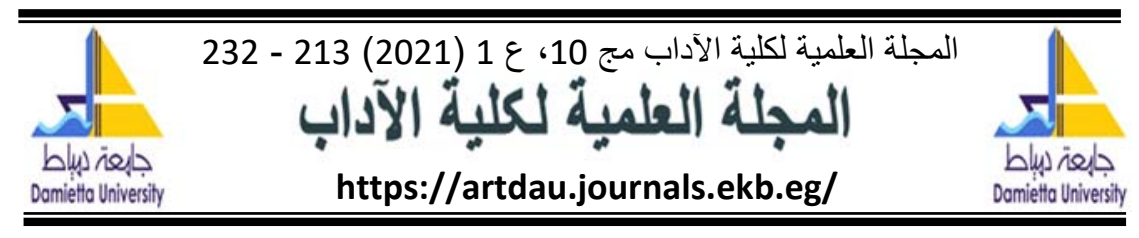

\title{
الاحتلال السوفيتي لأفغانستان 1979 - 1989 م
}

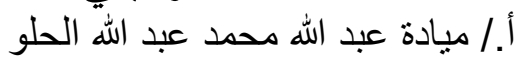

(1) طالبة دكتور اه، قسم التاريخ - كلية الآداب ـ جامعة علد دمياط.

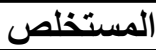

يُعد الاحتلال السوفييتي لأفغانستان 1979 - 1989م إستكمالاً لفترة الحرب الباردة

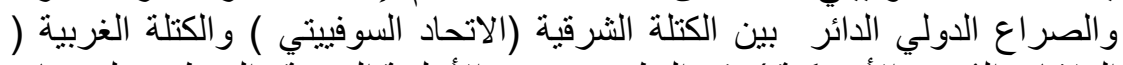

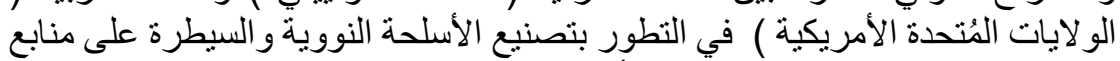

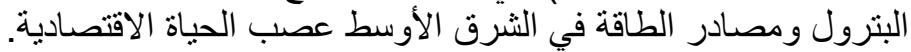

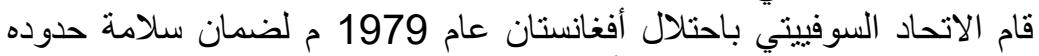

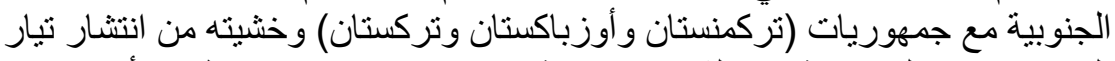

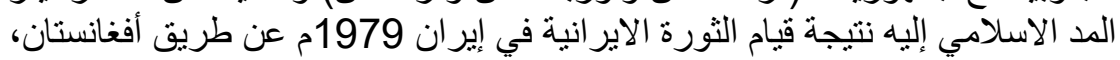

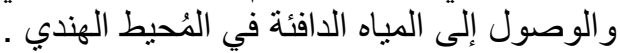

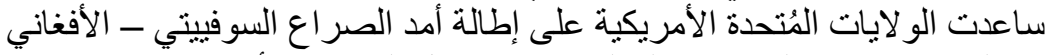

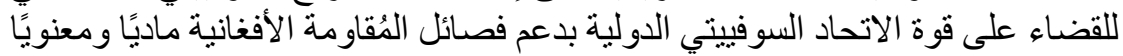

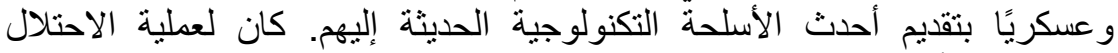

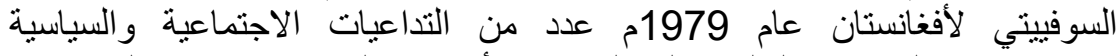
والاقتصادية والعسكرية السلبية على المجتمع الأفغاني و السوفييتي منها تفكلك الاتحاد

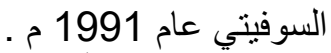

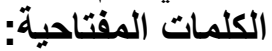

أفغانستان، الاحتلال السوفيتي

تاريخ المقالة: - ت تاريخ

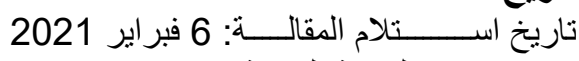
تاريخ استلام النسخة النهائية: 23 فبر اير 2021 فاير 2021 تاريخ قبــــــول المقالــــــــة: 30 مارس 2021 فيراير 2021 


\section{1 تداعيات الاحتلال السوفييتي لأفغانستان}

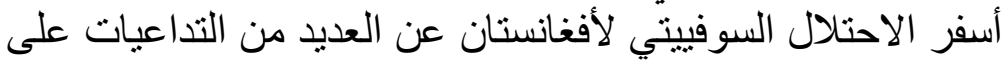

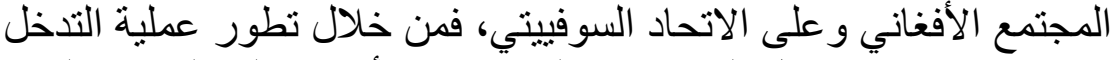

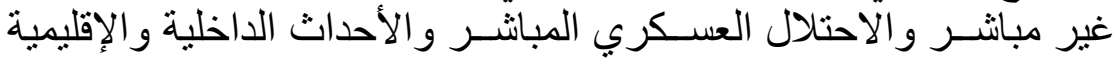
و الدولية، يمكن معرفة هذه التداعيات اليُترتبة على عملية الاحتلال.

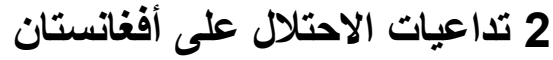

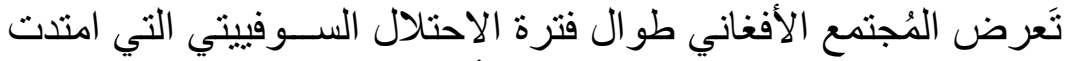

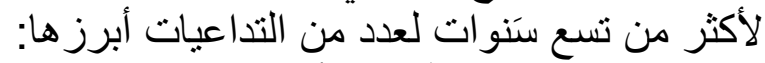
1.2 الخسائر الضخمة في الضئ الأرواح

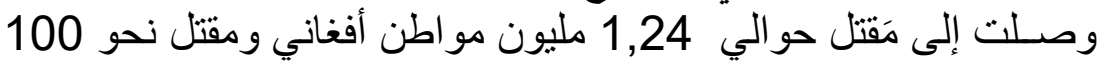

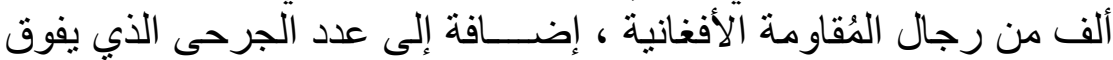

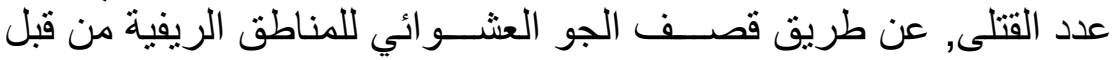

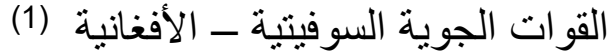
2.2 انتهاكات حقوق الإنسان في أفغانستان

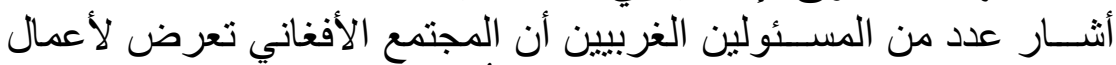

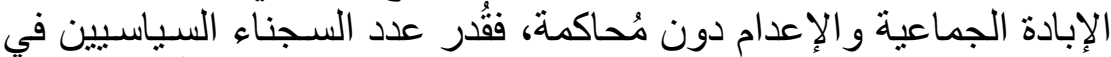

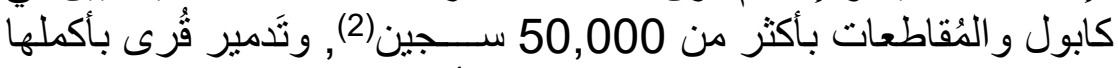

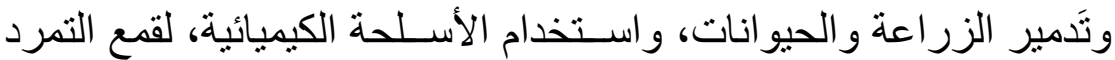

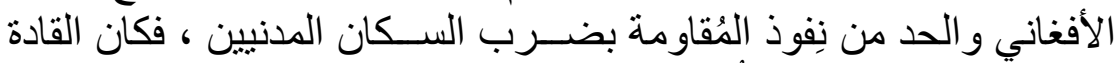

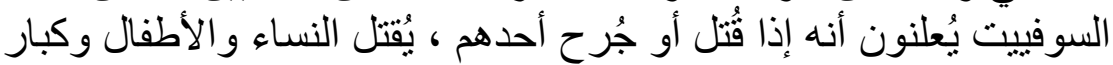
السن (3)

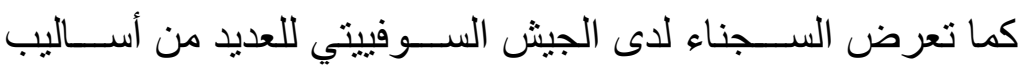

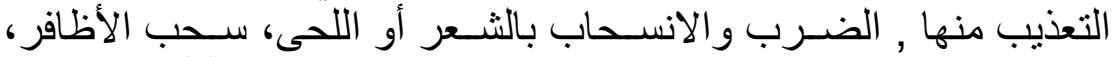

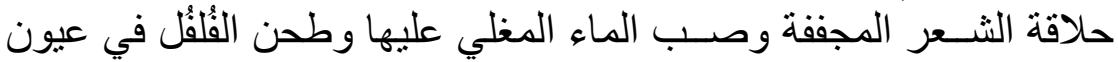

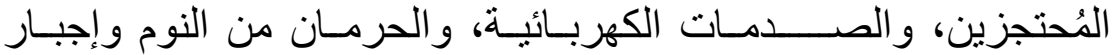
اللُحتجزين على الوقوف على الجليد أو في الثمس الحارقة، الحقن السـام، التها

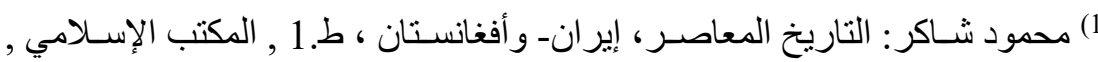

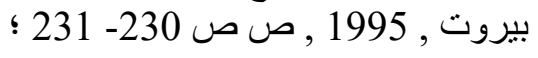

Asger Christensen: Aiding Afghanistan, The Back Ground And Prospects For Reconstruction In A Fragmented Society, Nordic Institute Of Asian Studies (N.I.A.S),1995 ,P.P 96 -97

(2) Rubin, B . R : Human Rights In Afghanistan In : R . Klass (E.D) Afghanistan The Great Game Rivited New York, 1987 , p . 342

${ }^{(3)}$ Alexiev Alexander : Inside The Soviet Army In Afghanistan, The RAND Corporation $1988, \mathrm{P}, 58$. 


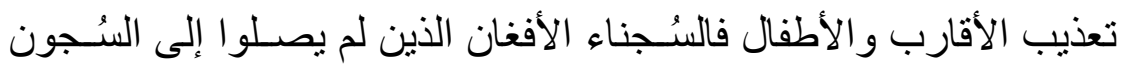

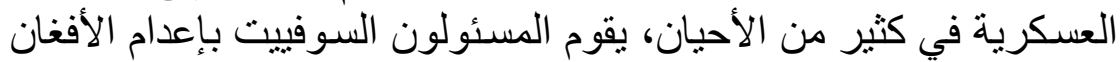

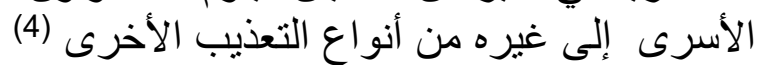

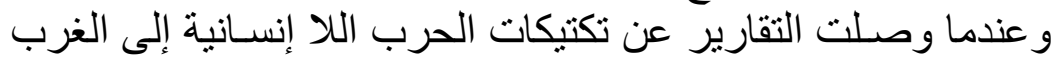

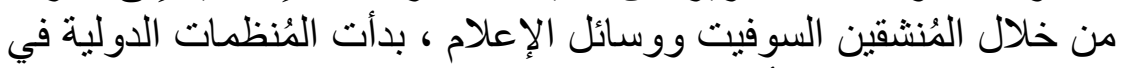

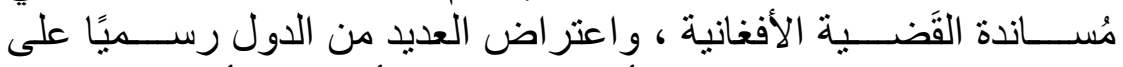

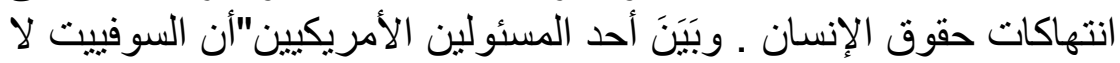

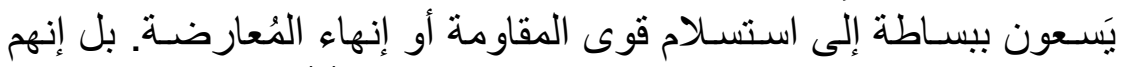

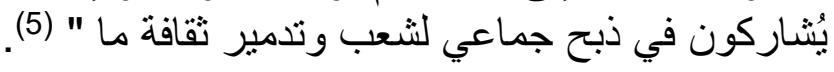
3.2 مُشكلة الناجئين

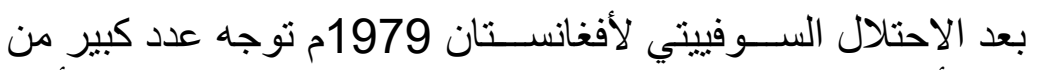

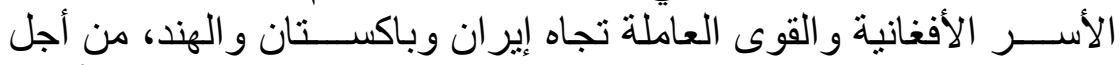

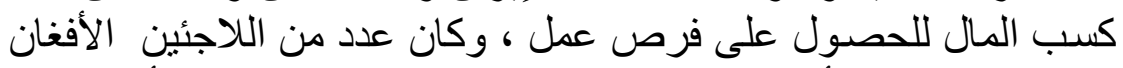

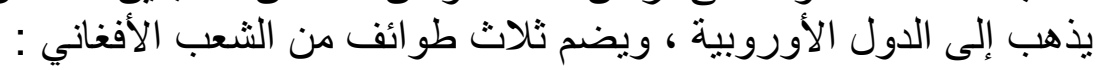
زعماء القبائل.

أصحاب الثروة و المال في البلاد.

العسكريين الأفغان (القوات العات العسكرية الأفغانية).

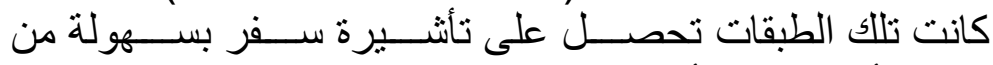

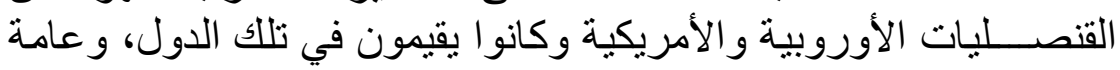

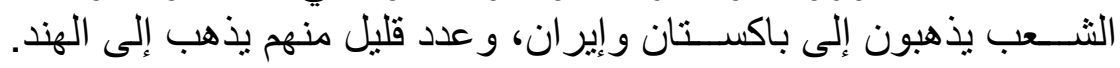

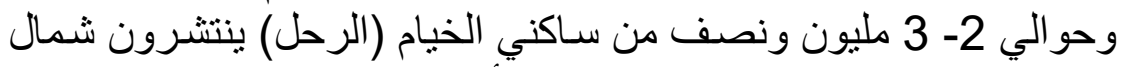

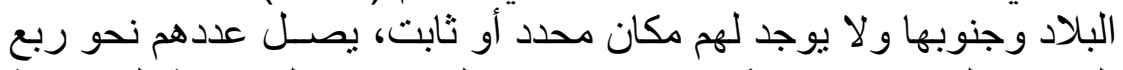

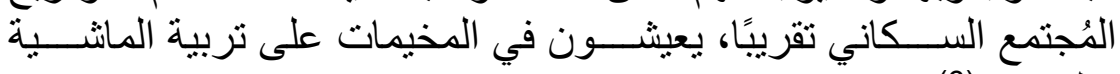
والتجارة (6)

(4) US National Committee for Human Rights In Afghanistan, Russia's Barbarism In Afghanistan, Vol. 11 , April 1985,P. 1 ; Amnesty International : Democratic Republic Of Afghanistan , Background Briefing On Amnesty Internationals Concerns , November, 1983 P . 9

(5) US House Of Congress : Hearing Before The Commission On Security And Cooperation In Europe, Soviet Violations Of The Helsinki Accords In Afghanistan, 1985, p. 17.

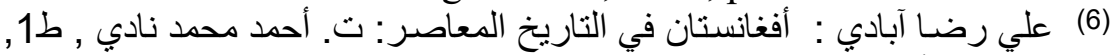

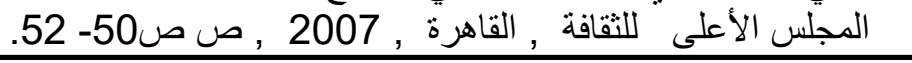


سبب الاحتلال السوفييتي لأفغانستان 1979م تدهورًا في شـئون

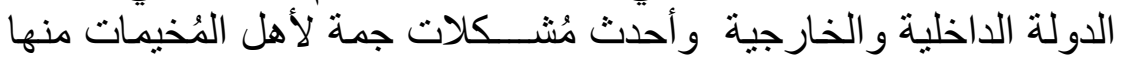

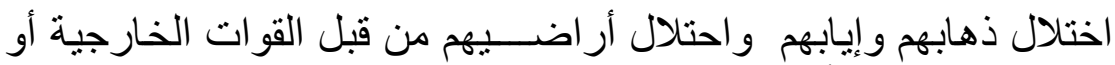

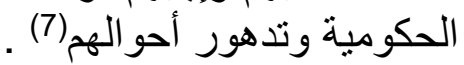

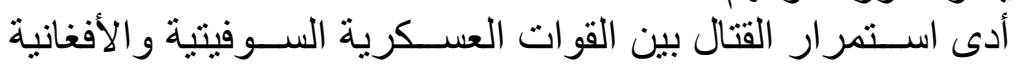

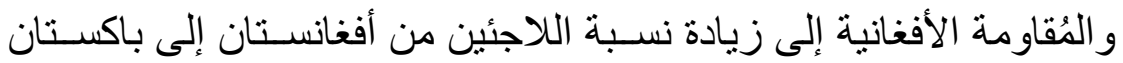

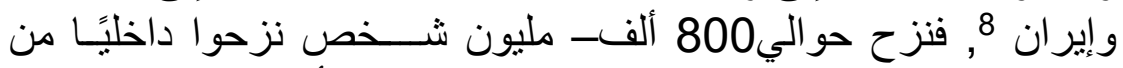

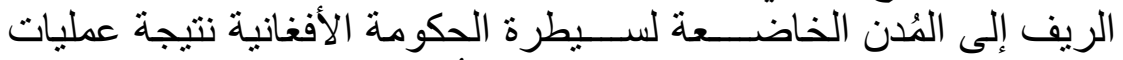

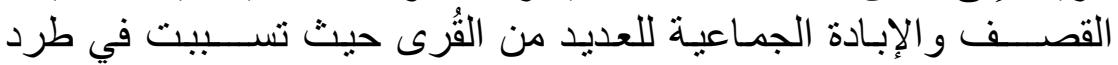

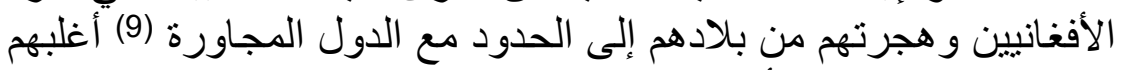

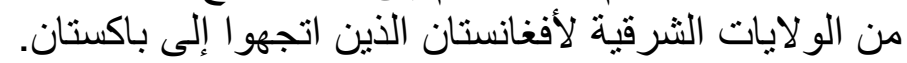
جدول (1) عدد اللاجئين الأفغان في العايد من الدول التين

\begin{tabular}{|c|c|}
\hline نسبة اللاجئين & الدولة \\
\hline 2, 3 مليون نسمة & باكستان \\
\hline 2 مليون نسمة & ايران \\
\hline 150 ألف نسمة & الدول الغربية \\
\hline 50 ألف نسمة & الجزيرة العربية \\
\hline 10 آلاف نسمة & تركيا \\
\hline
\end{tabular}

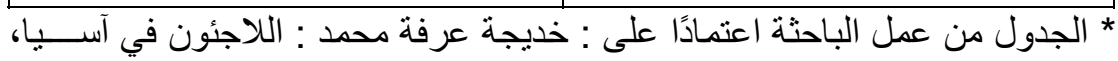

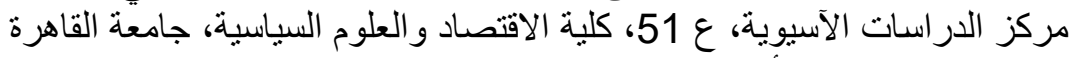

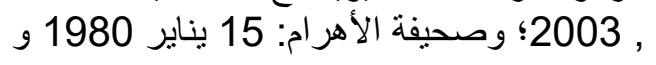
Bruce Amstutz : Afghanistan The First Five Years Of Soviet Occupation National Defence University Washington, D. C. 20319- 6000, 1980, PP145- 146

$$
\text { (7) (7) المرجع نفسه : ص: 40-50. }
$$

(8) The Economic Impact Of Soviet Involvement In Afghanistan (U) : Department Of Defence Intelligence Document, April . 1983

(9) Elliott Newton: Op . Cit , P. 32 ; Van Royen .R : Repatriation Of Afghan Refugees, AUNHCR, Perspective In Afghanistan Looking Into - The Future Institute Of Strategic Studies, Islam Abad, 1990, P . 54 . 


\section{نسبة اللاجئين}

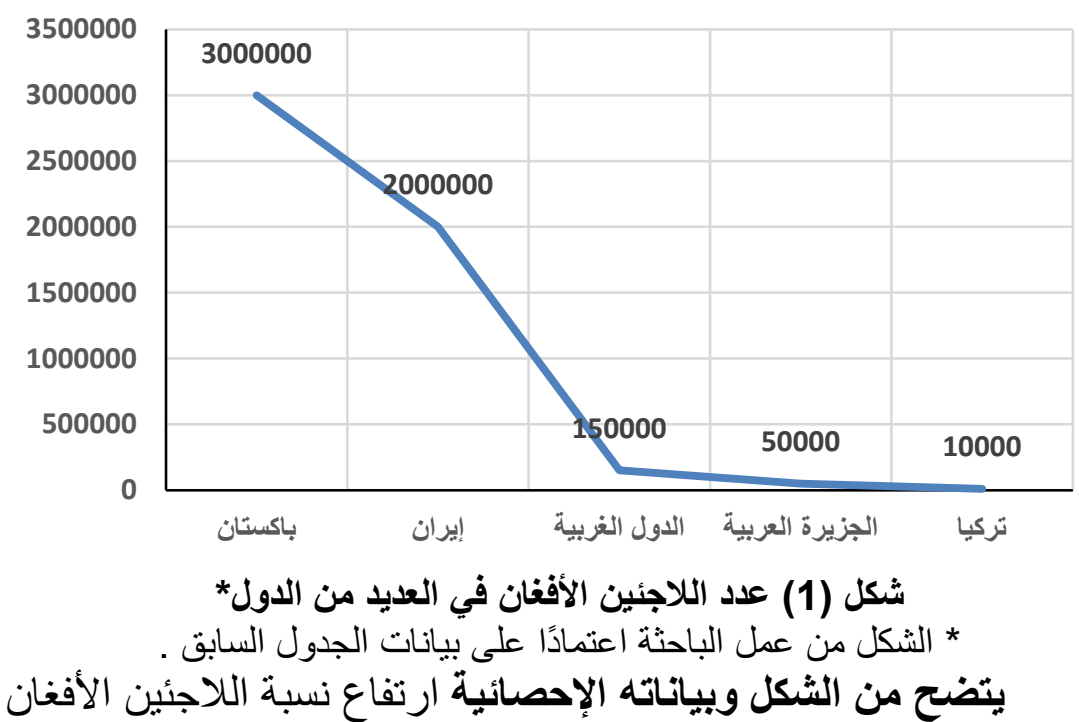

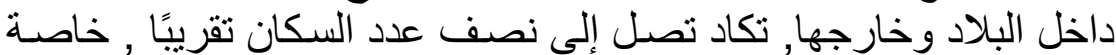

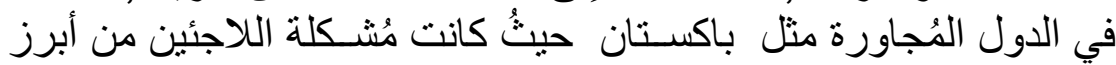

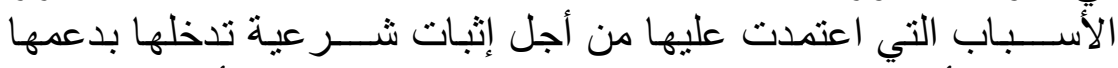

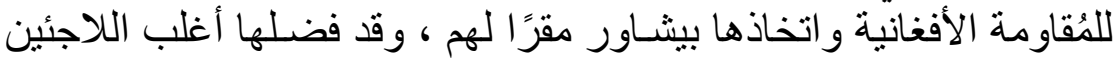

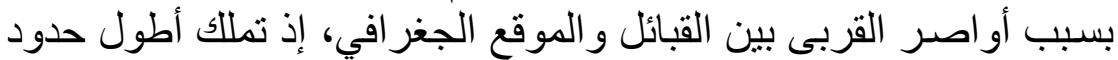

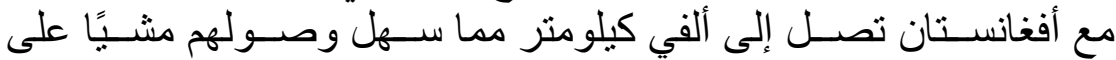
الأقدام، فقطعوا الوديان عبر الجبال دون جواز ات سفر أو أو تأثنير ات دخول

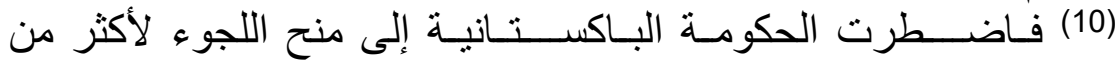

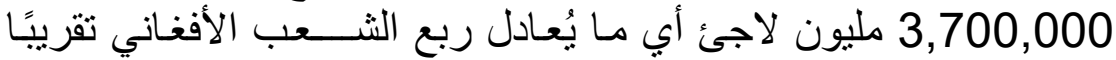

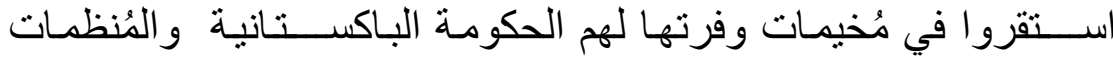

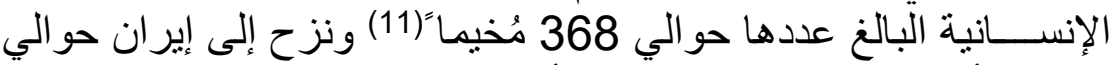

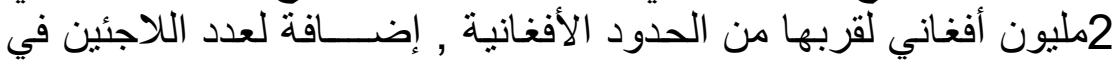

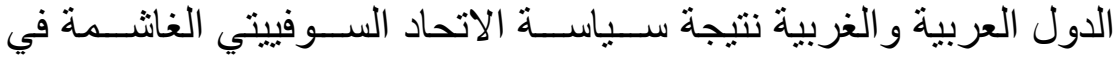

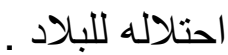

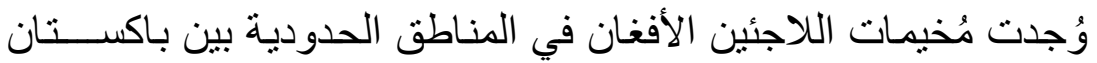

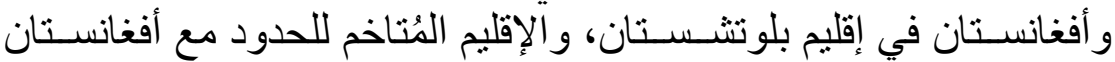

(10) Christinlamb : waiting for Allah Pakistan's Struggle For Democracy Tallish , Oxford University, London , 1991,P. 129

(11) Antonio Haman : Pakistan After Zyaa , Asia Publishing House , London, 1988,P. 75 . 
(الإقليم الحدودي الثمالي الغربي) تم تقسيمهم على حسب القبيلة و العرق,

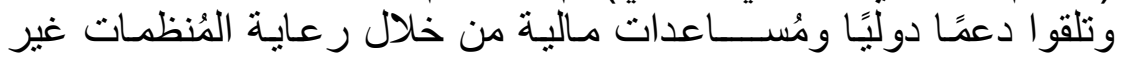

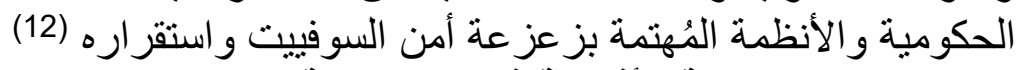

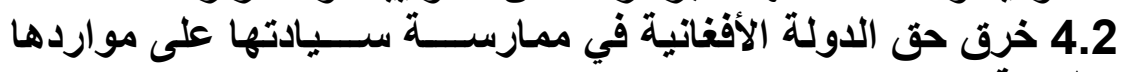

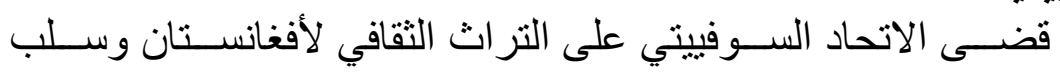

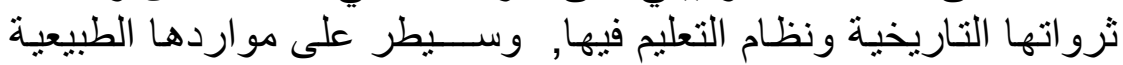
وثرو اتها القومية ودمر العديد من المتاحف ونهب مُحتوياتياتها وقام بإرسالها

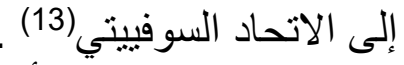

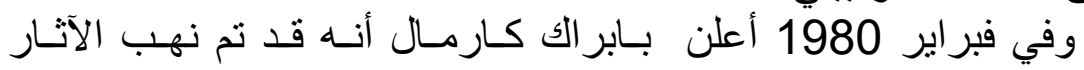

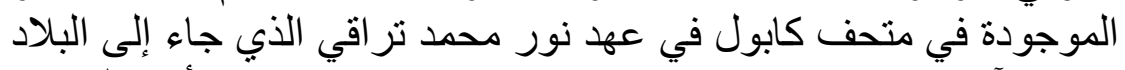

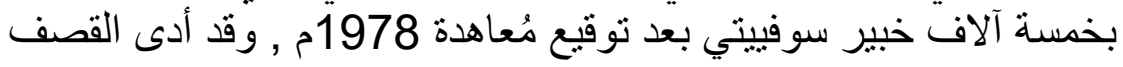

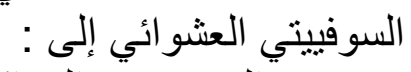

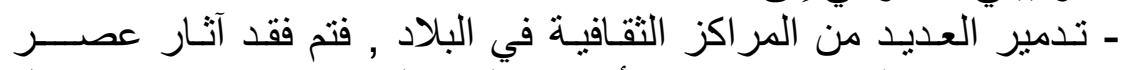

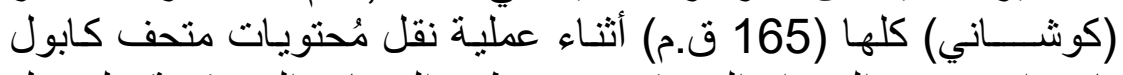

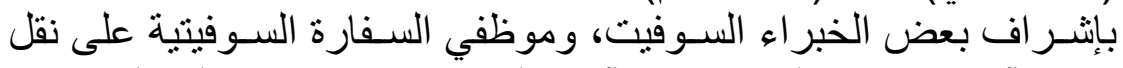

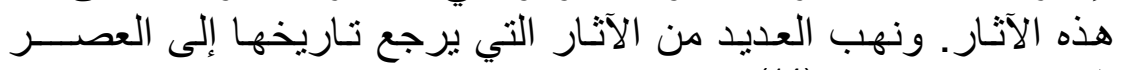
الباختري الإغريقي (14).

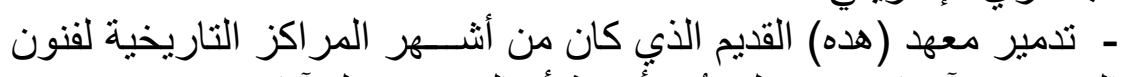

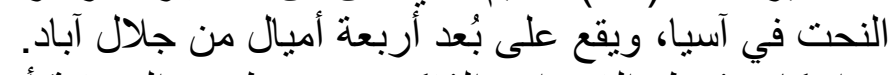

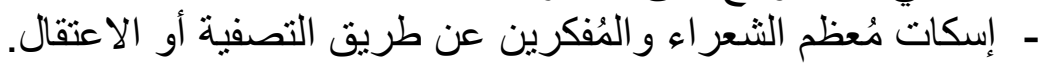

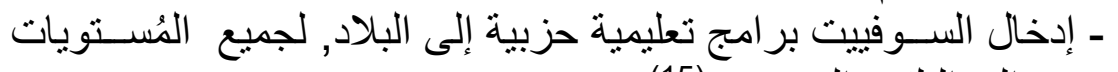
تهاف إلى التلقين الحزبي . (15)

(12) - This is a repository copy of Spooks, Tribes, and Holy Men: The Central Intelligence Agency and the Soviet Invasion of Afghanistan : University Of Ieeds, Https : //Eprints. Whit Rose .Ac.Uk

(13) :The Economic Impact Of Soviet Involvement In Afghanistan

(U) Department Of Defence Intelligence Document, April . 1983

(14) Remote assessments of the archaeological heritage :Emily Hammer situation in Afghanistan, Afghanistan Cultural heritage Satellite imagery Archaeology Spatial analysis , 2017 , P127. Augus Available online at Science Direct www.sciencedirect.com

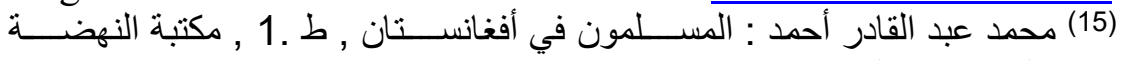
المصرية , القاهرة , 1984 ص ص صد في 96- 97. 
- مُحاولة الســوفييت احتكار عملية الكثــف عن الآتار، فتم إيقاف جميع

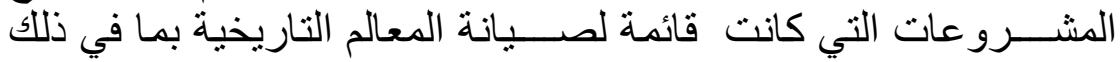

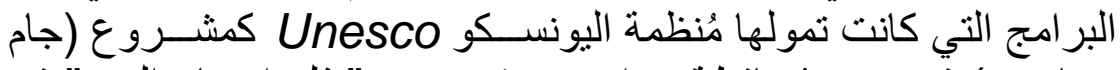

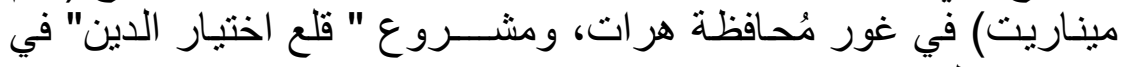

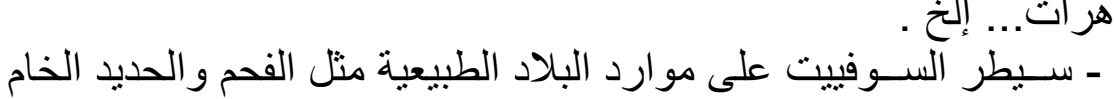

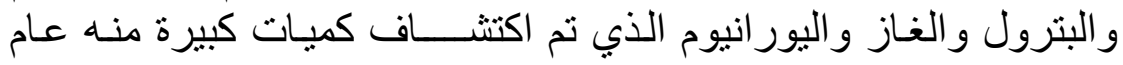

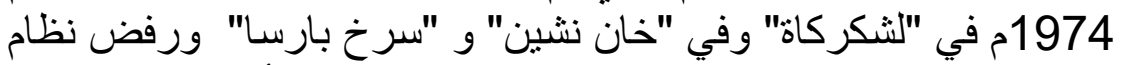

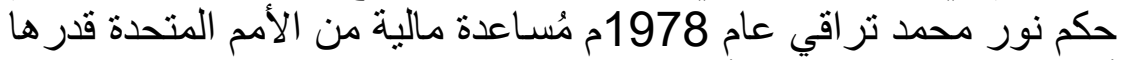

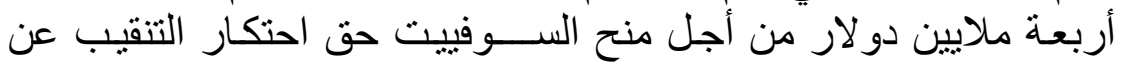

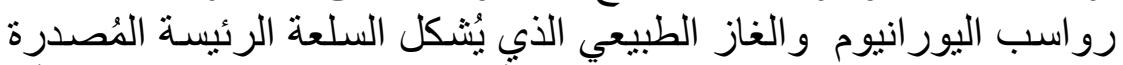

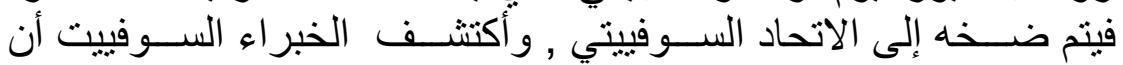

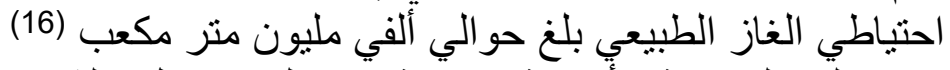

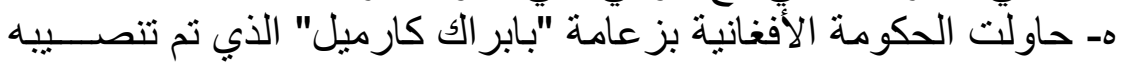

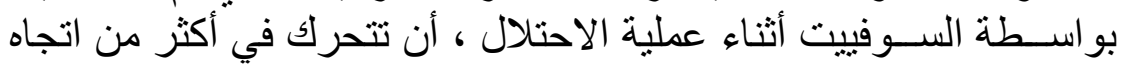

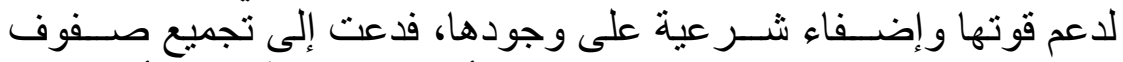

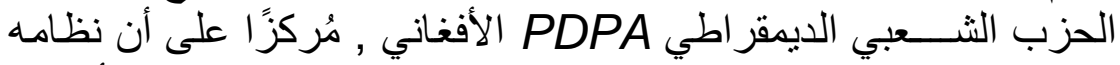

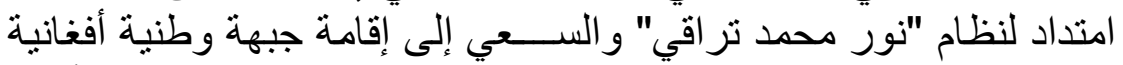

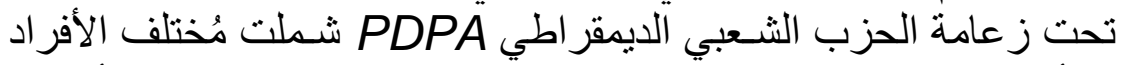
و الأحز اب ورجال الدين ومختلف القوى الوطنية على الســــاحة الأفغانية

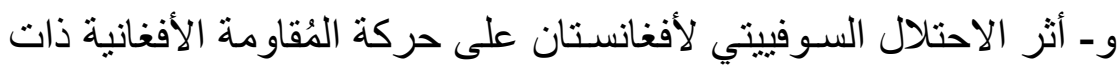

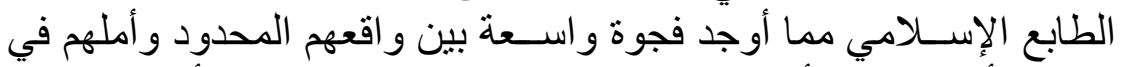

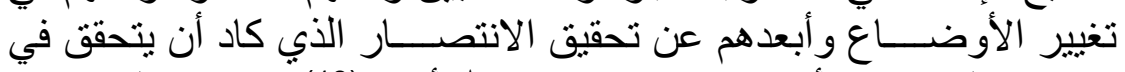

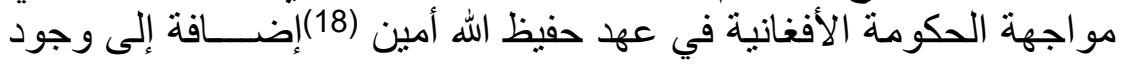

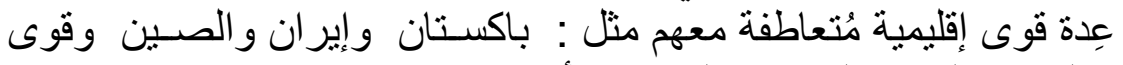

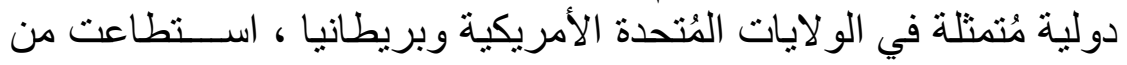

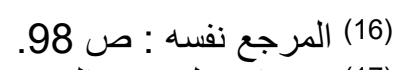

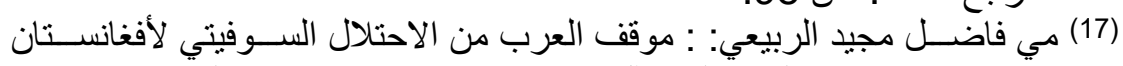

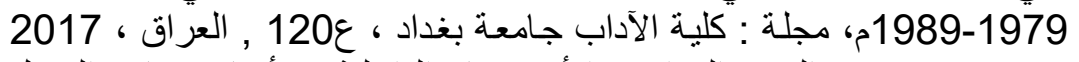

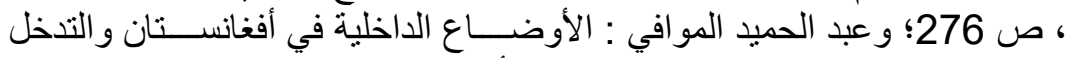

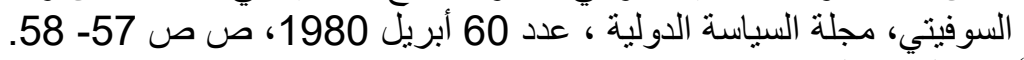

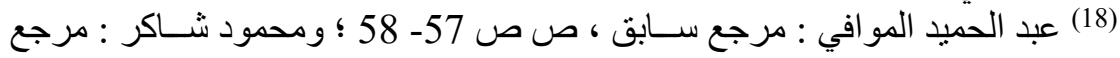
سابق ، ص ص 264- 292. 


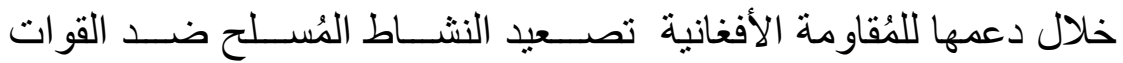
السوفيتية(19). ي - أدت عوامل التحدي نتيجة استمر ار الوجود السوفييتي في أفغانستان

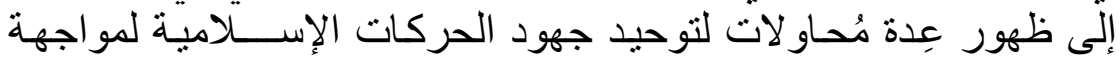

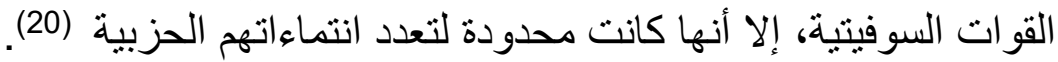

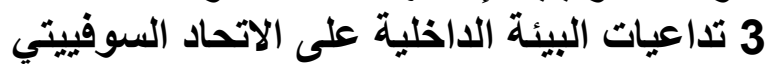

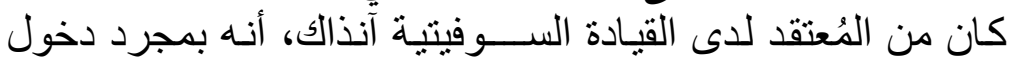

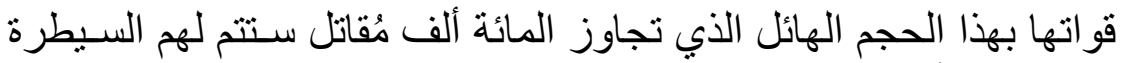

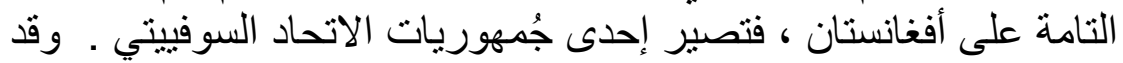

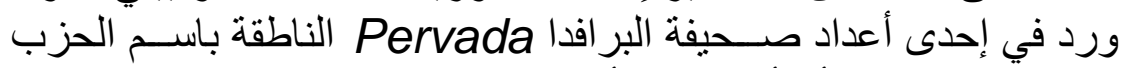

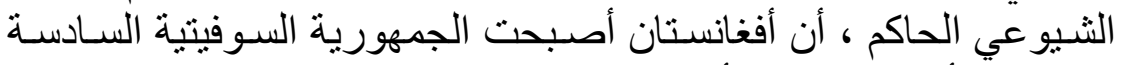

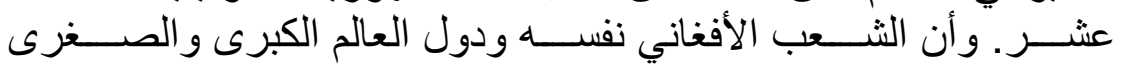

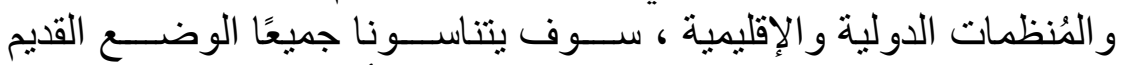

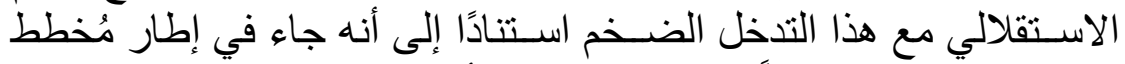
من جانب ألسوفيت تنفيذًا لوصية بطرس الأنس الأكبر (21)

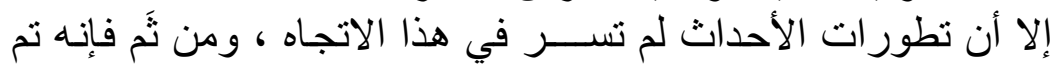

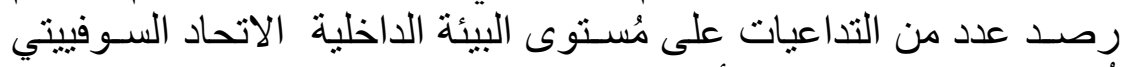

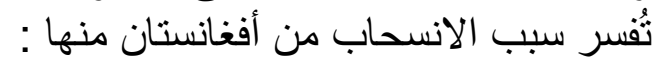
1.3 الآثار العسكرية

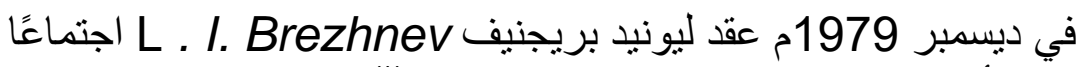

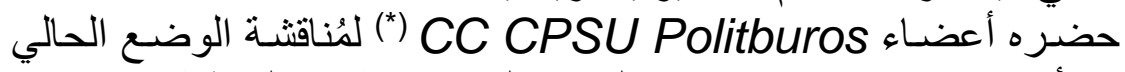

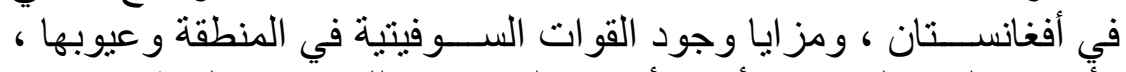

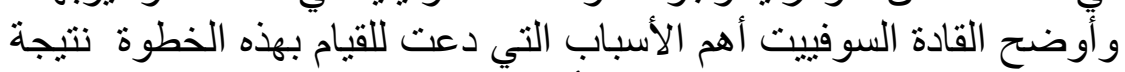

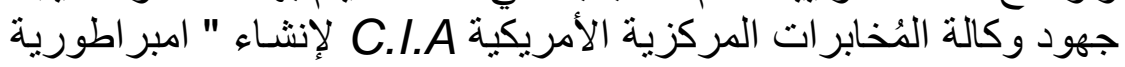

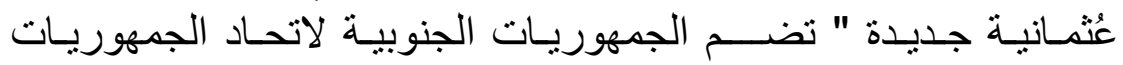

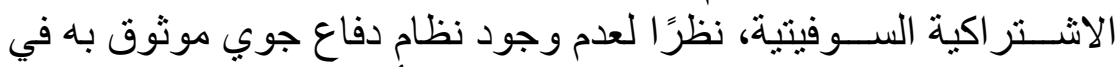

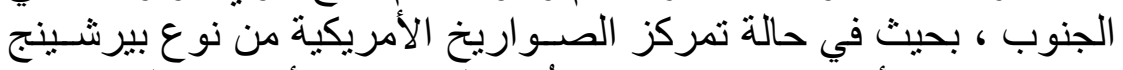

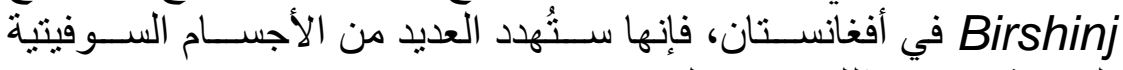

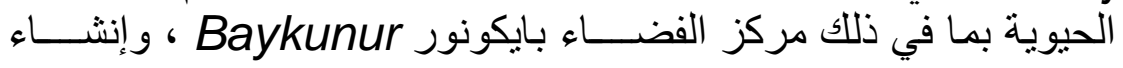

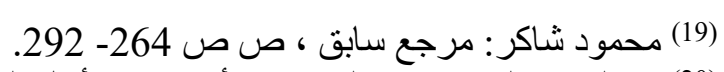

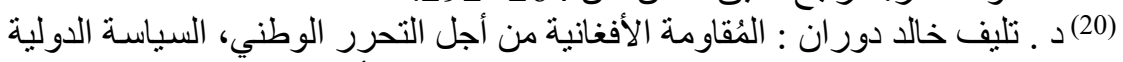

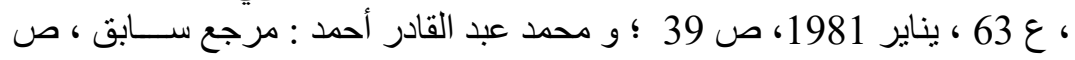
. $161-136$ (21) رالف هـ. ماجنوس : مشكلة أفغانستان ، ت : صليب بطرس روفائيل مسيحة ، د د.

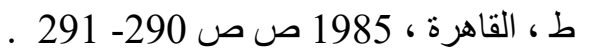




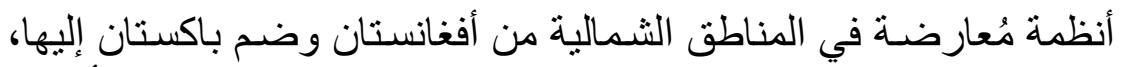

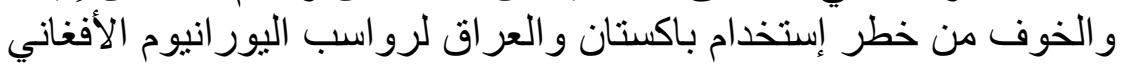

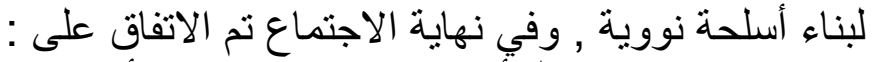

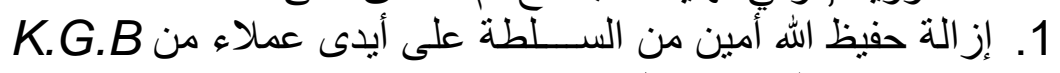

$$
\text { ووضع بابر الك كارميل مكانه. }
$$

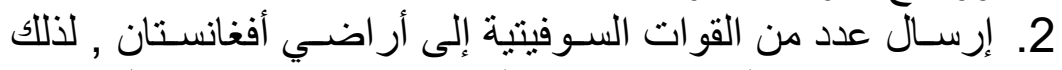

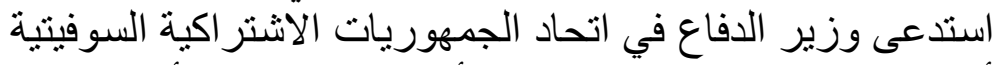

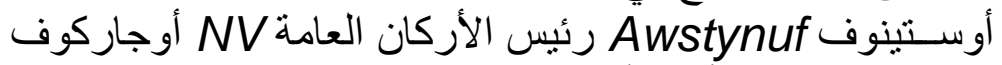
Awjarakuf

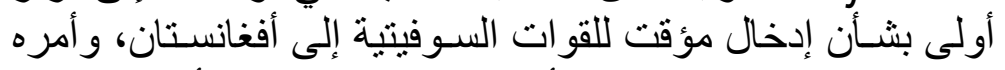

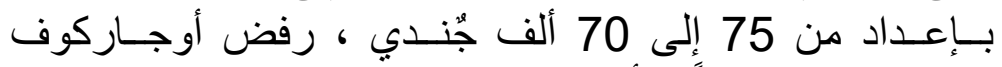

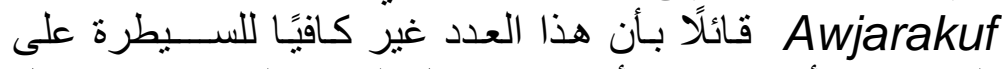

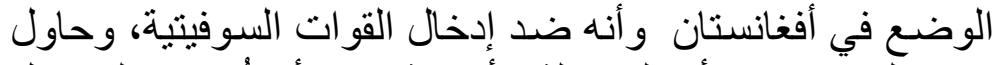

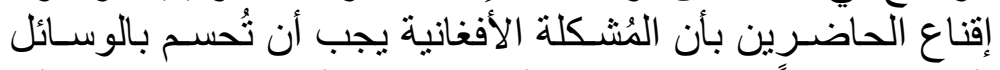

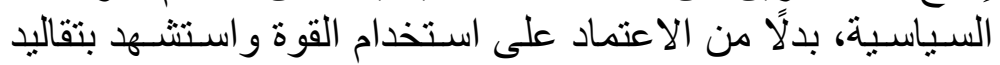

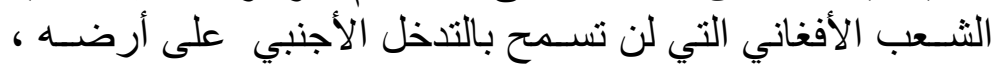

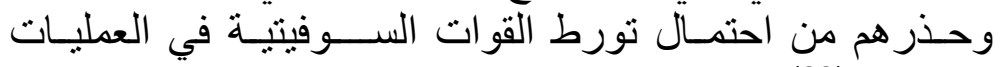
العسكرية (22).

ومع ذلك تم إتخاذ القرار باستخدام القوات السوفيتية في أفغانستان،

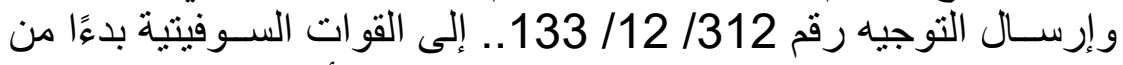

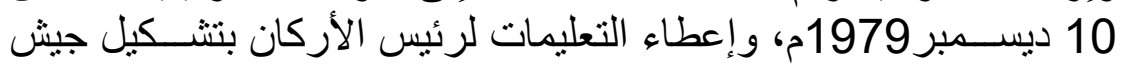

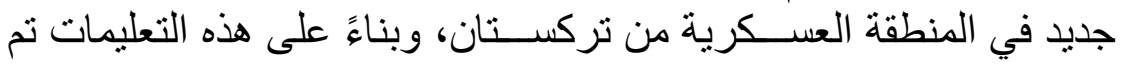

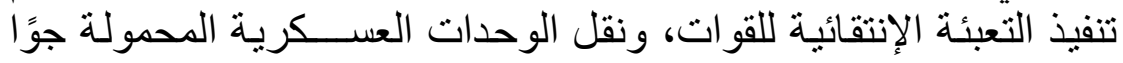

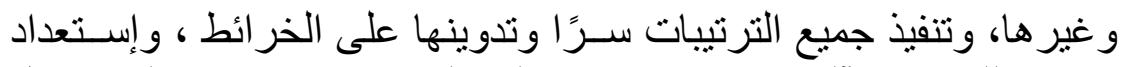

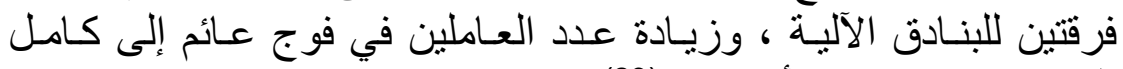

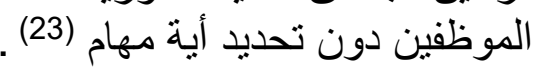

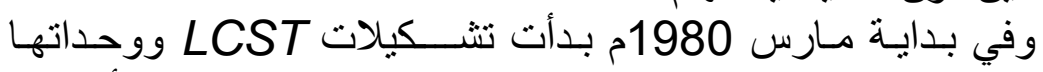

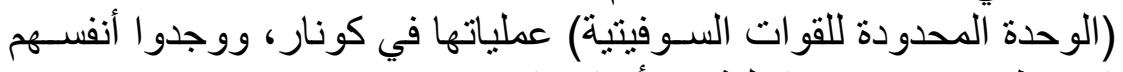
مُنورطين في حرب داخلية في أفغانستان .

${ }^{(22)}$ Alexander lyakhovsky : The Tragedy And Valor Of Afghan C . p. I Iskon, Moscow 1995, P.P $1-2$.

(23) Georgy M. Kornienko : The Cold War, When And Why The Decision To Send Troops To Afghanistan, Testimony Of Aparticipant, Moscow, Mezhdun Arodnye Otno Sheniya, 1994 p. 2. 


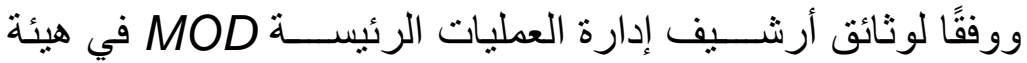

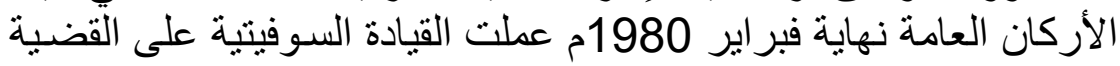

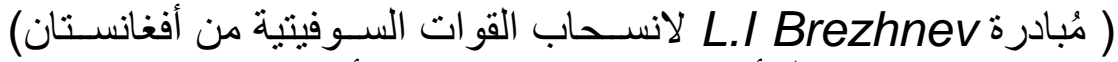

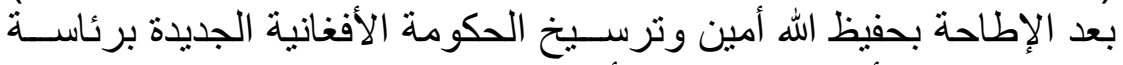

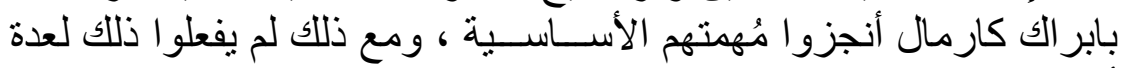

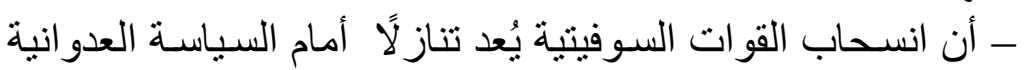

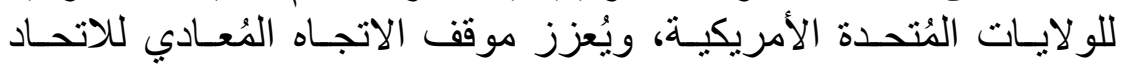

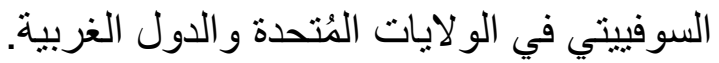

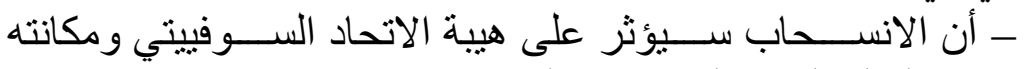

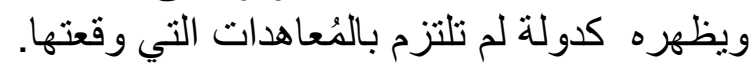

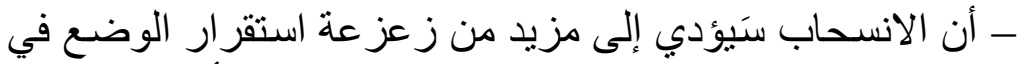

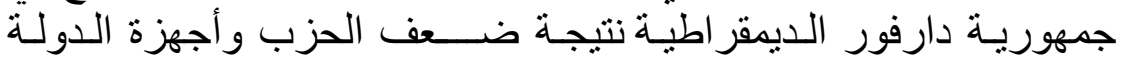
و القوات المُسلحة مما يؤدي إلى فقدان أفغانستان. - سـيترتب عليه نمو التطرف الإســلامي بالقرب من فئن حدود الاتحاد

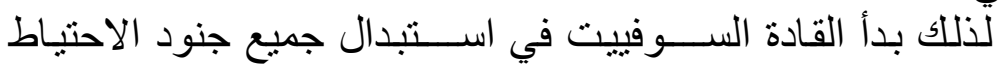
العسكريين بضباط و أفراد مُجندين على النحو التالّي : نم استبد التبدال

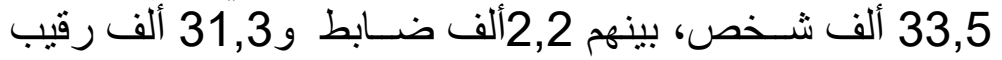

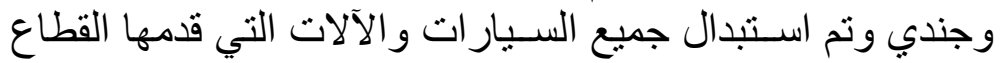

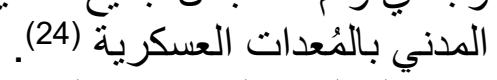

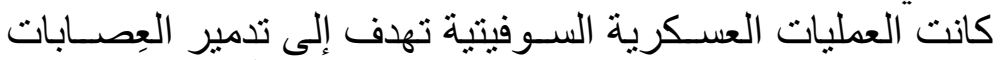

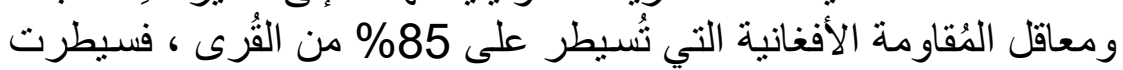

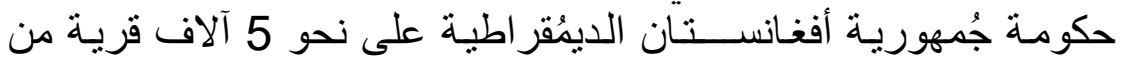

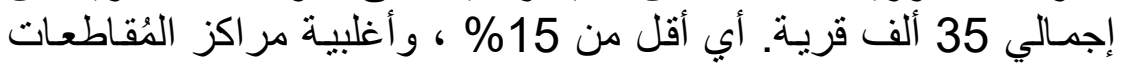

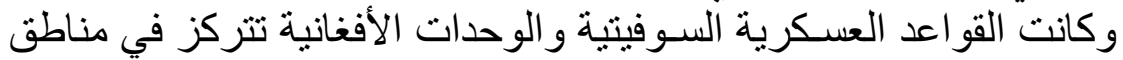

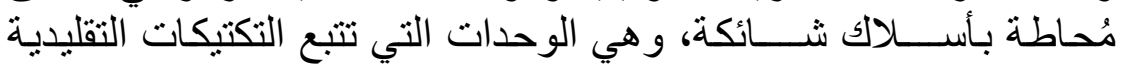

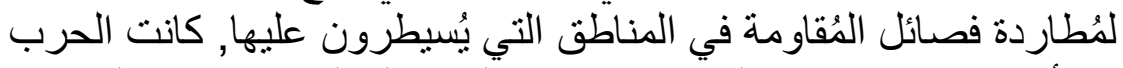

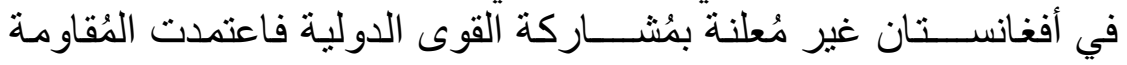

(24) Alexander Lyakhovsky: The Tragedy And Valor Of Afghan, On The Changing Mission Of The Soviet Forces In Afghanistan, Moscow, G.p.I , Iskon, 1995, p. 2 . 
الأفغانية في صر اعها مع السوفييت على العلاقات القبلية القديمة والمناطق

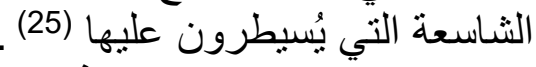
جدول (2) خسائر الجيش السوفئروني واليها والمقاومة الأفغانية عام 1982م بمحافظة

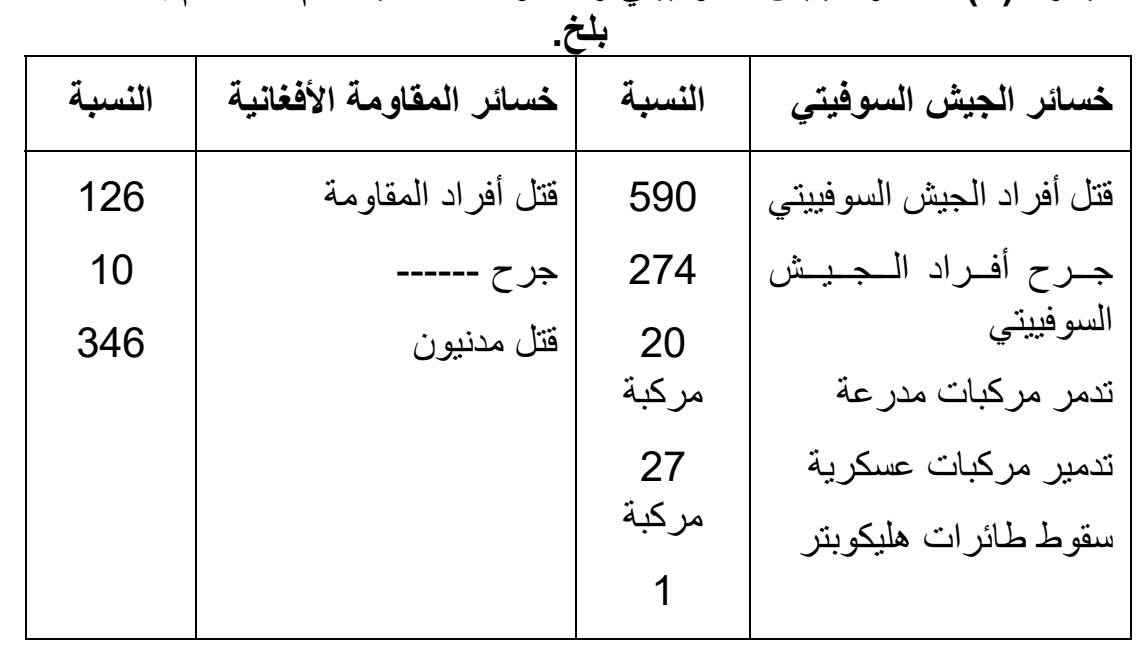

BRUCE AMSTUTZ : Afghanistan The First Five Years Of Soviet Occupation : National Defense University Fe\$y Washington ,1987 , p165.

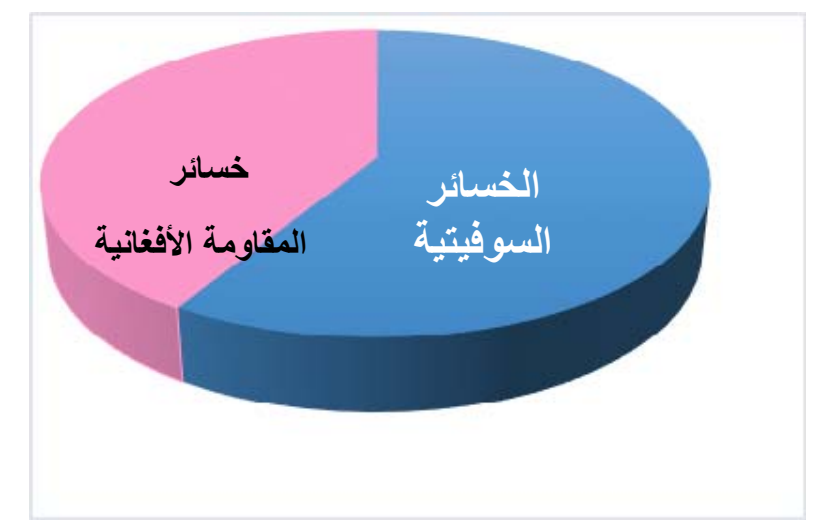

شكل (2) خسائر الجيش السوفييتي والمقاومة الأفغانية

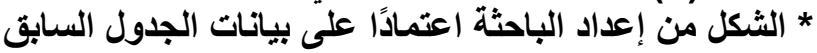

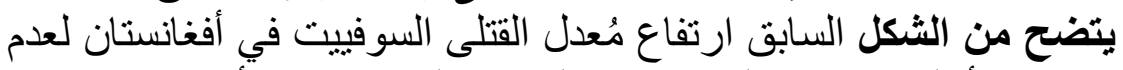

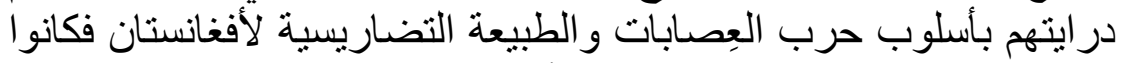
عديمي الخبرة بحرب الجبال ، وكان أسلوب القتال السوفييتي يعتمد لأنيان

(25) Pravda : Corres Pondent I. Sh Chedrov's Letter To The CCCPSU On The Situation In Afghanistan , November 12, 1981, p.p. 1-2. 


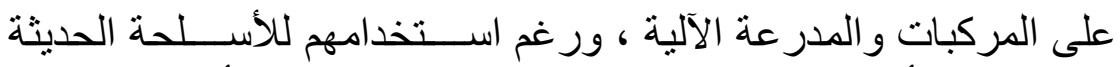

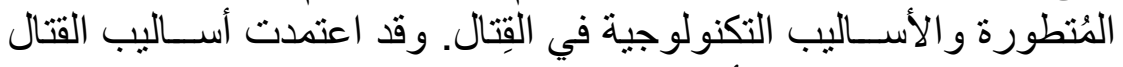

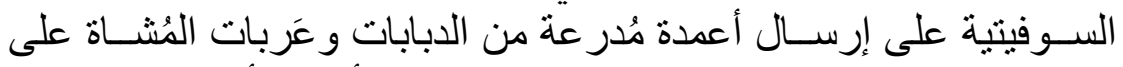

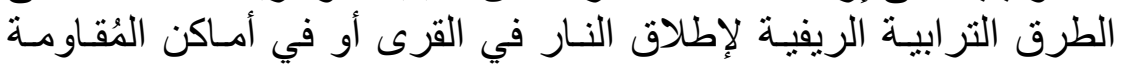

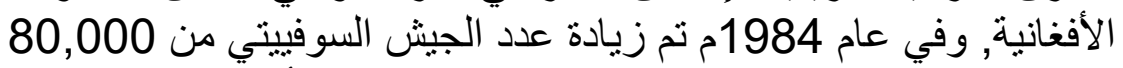

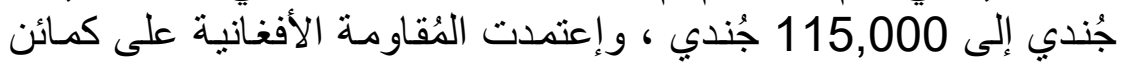

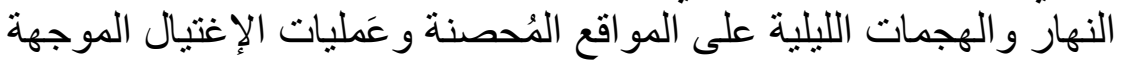

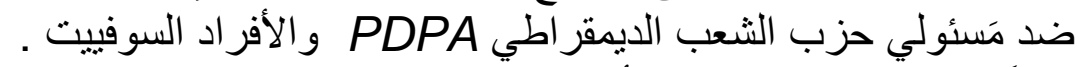

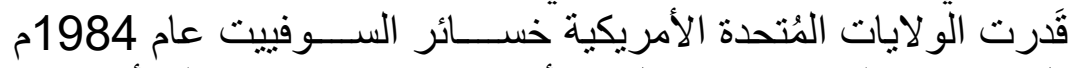

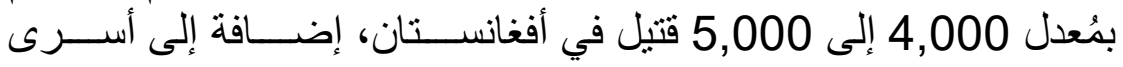

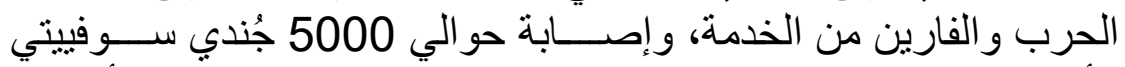

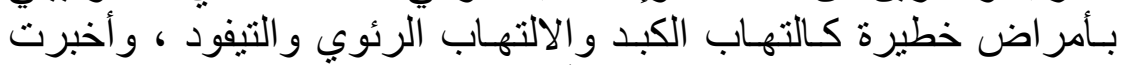

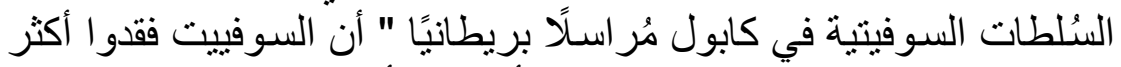

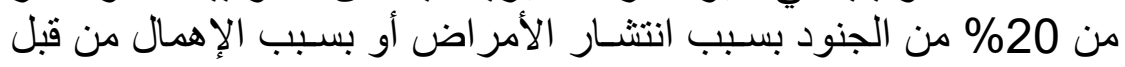

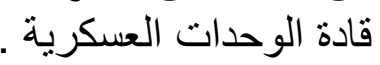

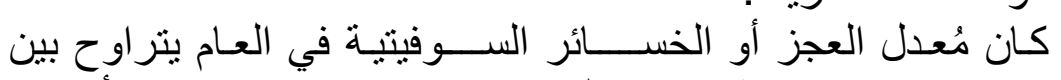

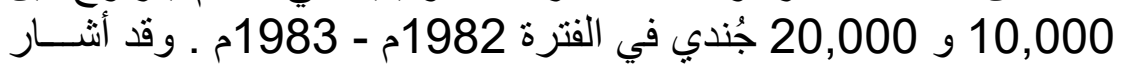

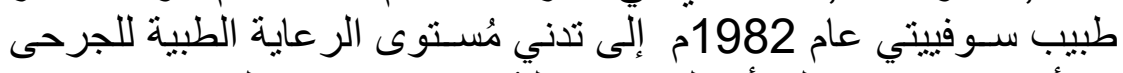

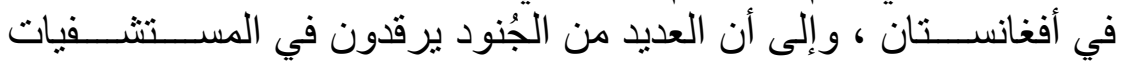

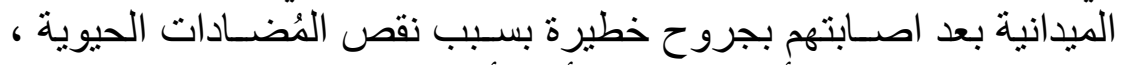

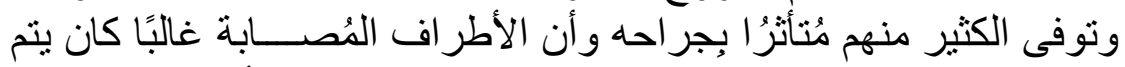

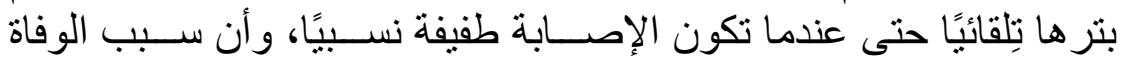

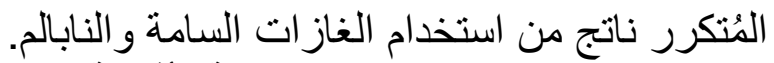

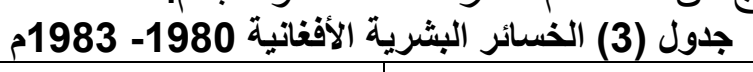

\begin{tabular}{|c|c|}
\hline النسبة & الخسائر البشرية \\
\hline 50.000- 100.000 شخص & المقاومة الأفغانية \\
\hline 100.000- 200.000 شخص & المدنيون \\
\hline
\end{tabular}

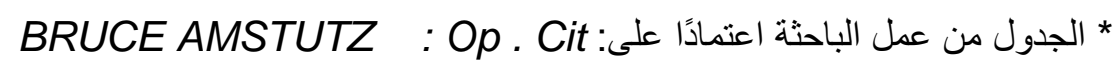
, p 163 . 


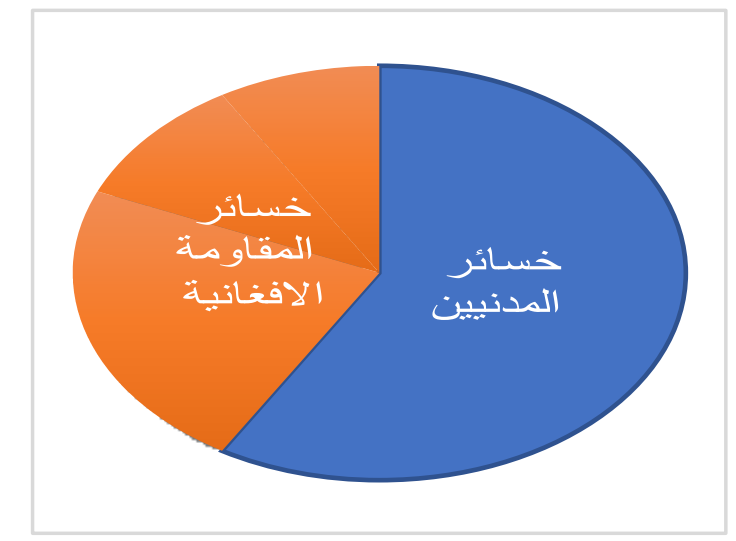

شكل (3) الخسائر البشرية الأفغانية 1980- 1983م

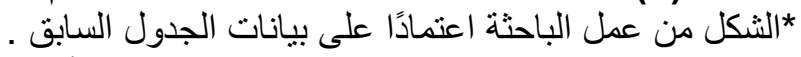

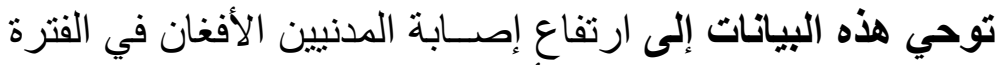

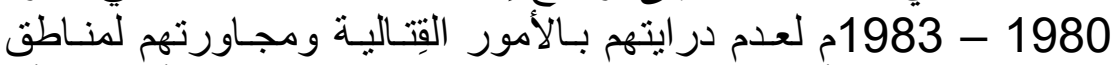

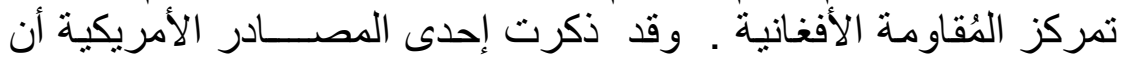
خسائر المُعدات السوفيتية تجاوزت الافية 2,5 مليار دولار خلال عام 1983م

جدول (4) المُعدات التي خسرها الجيش السوفييتي والمُقاومة الأفغانية في الفترة 1982 - 1979

\begin{tabular}{|c|c|}
\hline خسائر المقاومة الأففانية & الخسائر السوفيتية \\
\hline 164 طـائرة بمـا في ذلــك طـائر ات & 546 طائرة، بما فيها طائر ات هليكو بتر \\
\hline هليكوبتر & 304 دبابة \\
\hline & 436 ناقلة أفر اد مصفحة \\
\hline 230 من طاقم الطائرة & 2758 مركبة أخرى \\
\hline
\end{tabular}

Alexander Lyakhovsky, Tragedy and Valor of Afghan, Iskon, Moscow 1995, Appendix 8, Translated by Svetlana Savranskaya , Document 21. CC CPSU Letter on Afghanistan, May 10, 1988. 


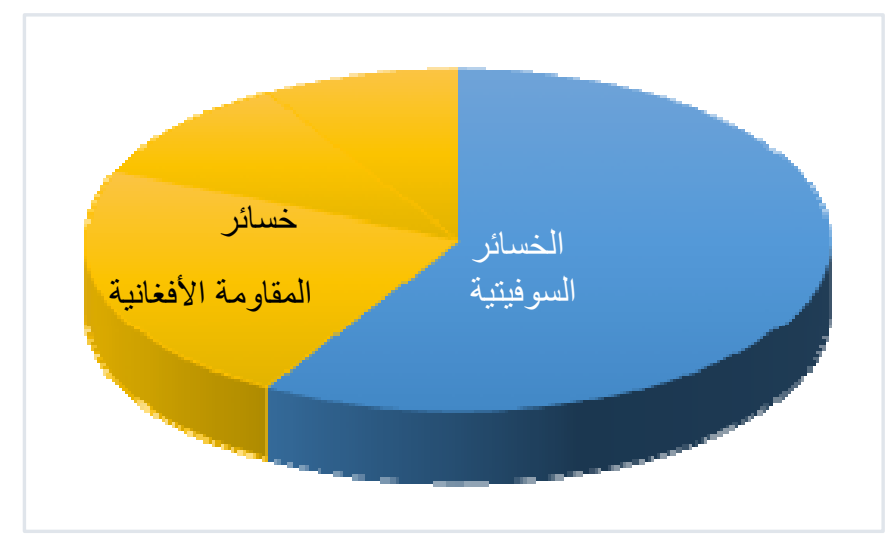

شكل (4) المُعدات التي خسرها الجيش السوفييتي والمُقاومة الأفغانية في الفترة 1979 - 1982 م. 1982

يتضـح من الشكل وبياناته الإحصـائية إرتفاع مُعدل الخسـائر السـوفيتية ماتئة

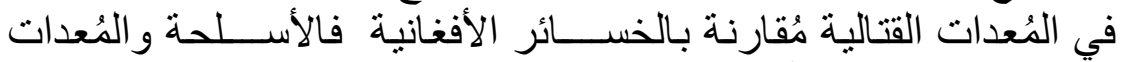

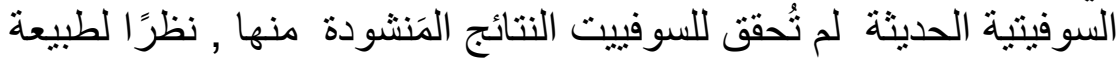

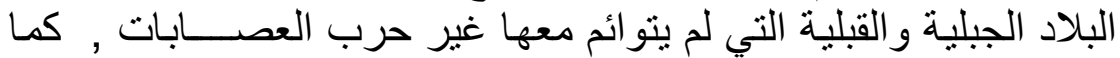

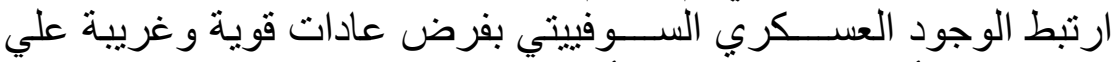

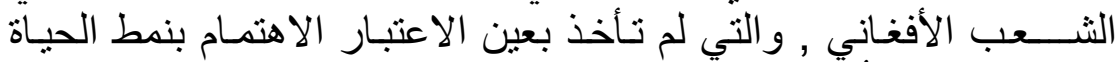

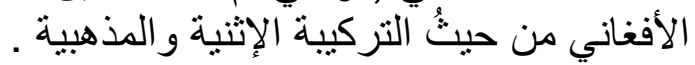

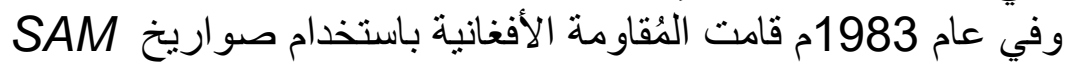

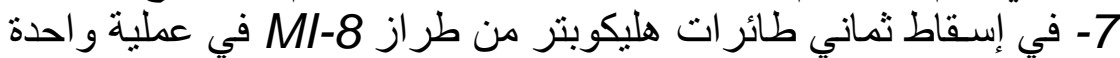

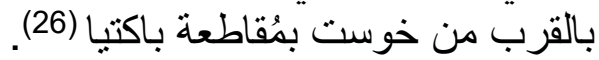

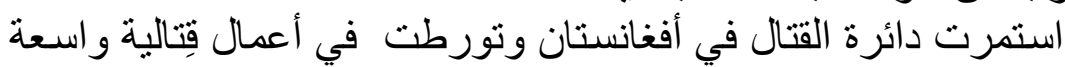

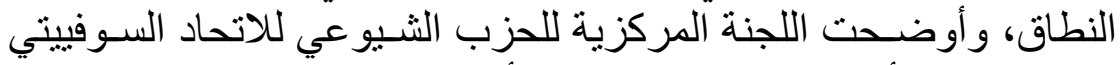
CCCPSU

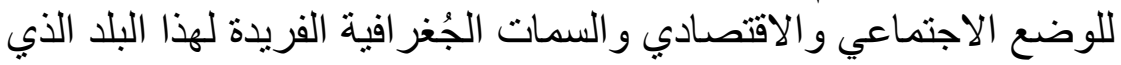

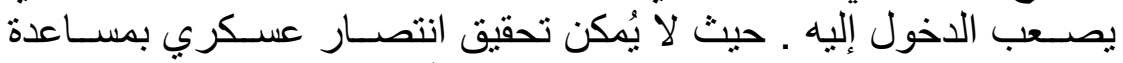

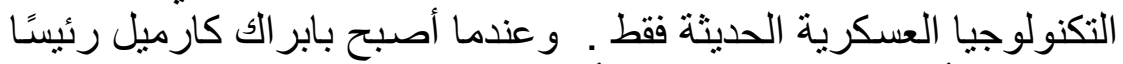

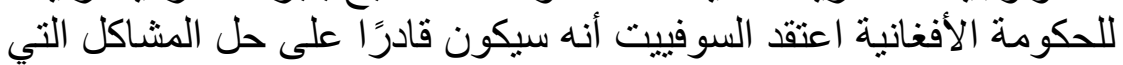

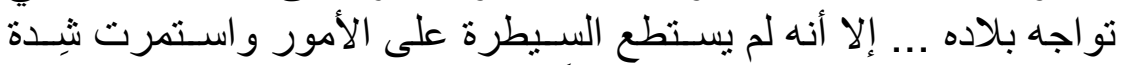

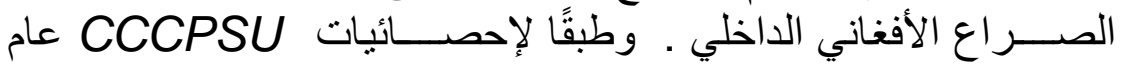
1988م ارتفعت خسائر الاتحاد السوفيتي في القتلى والجرحى . لإني

(26)BRUCE AMSTUTZ : OP . Cit, P.P 163- 164 
جدول (5) خسائر الاتحاد السوفيتي في القتلى والجرحى عام 1988م .

\begin{tabular}{|c|c|}
\hline نسبة الخسائر & نوعية الخسائر \\
\hline 101310 & القتلى \\
\hline 35478 & المصابون من الضباط و الجنود \\
\hline 301 & 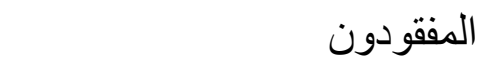 \\
\hline
\end{tabular}

الجدول من عمل الباحثة اعتمادًا :

Alexander lyakhovesky : Document 21- CCCPSU Letter On Afghanistan May 10 1988, Op . Cit, p. 1.

\section{كمية الخسائر}

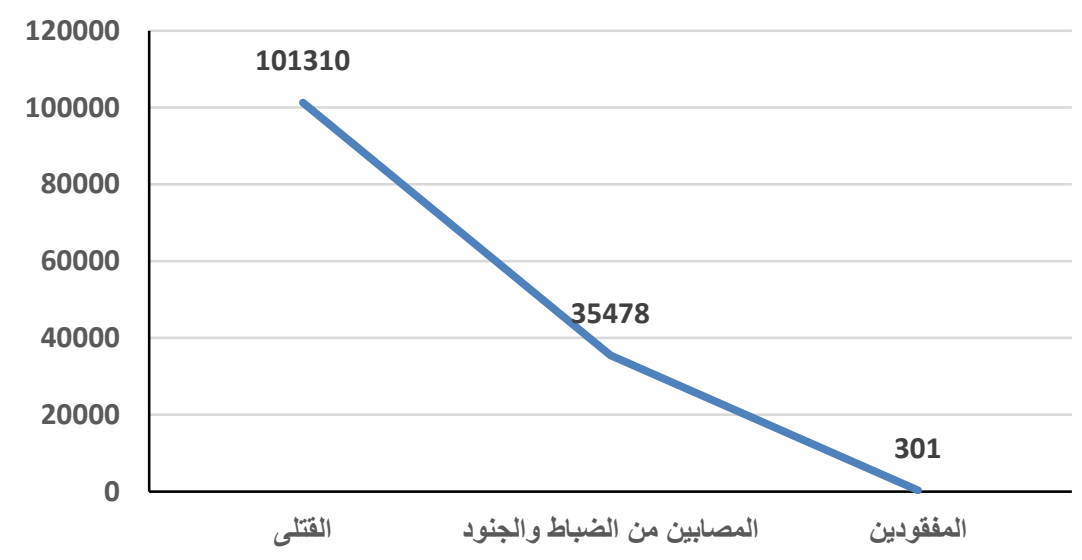

شكل (5) خسائر الاتحاد السوفيتي في القتلى والجرحى عام 1988م

* الثكل من عمل الباحثة اعتمادًا على بيانات الجدول السابق.

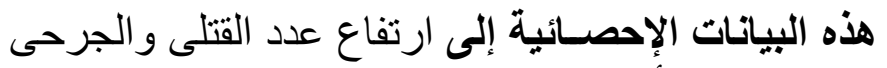

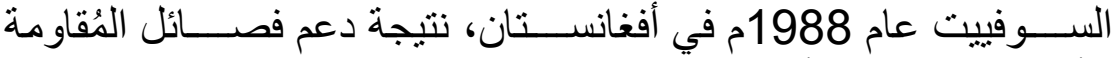

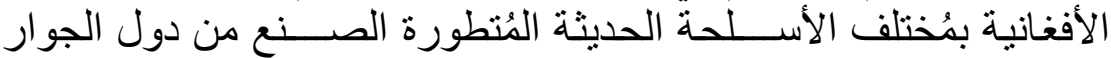

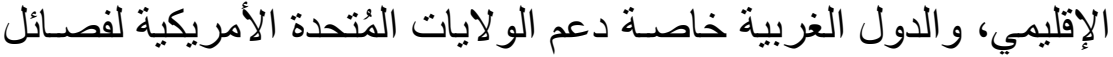

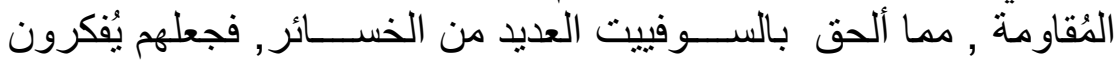

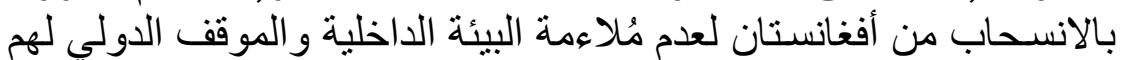




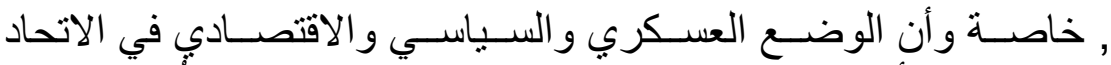

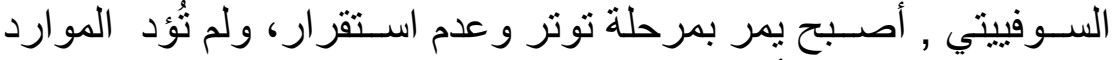

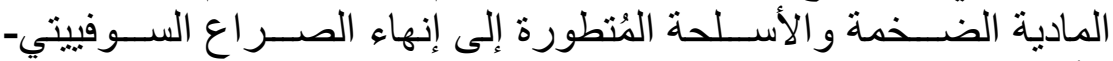
(27)

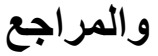

الافغاني

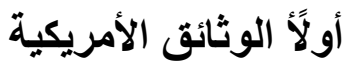

1-Alexander lyakhovsky : The Tragedy And Valor Of Afghan C. P . I Iskon, Moscow 1995.

2 ---------- : The Tragedy And Valor Of Afghan , On The Changing Mission Of The Soviet Forces In Afghanistan , Moscow, G.p.I , Iskon, 1995.

3 -----------: , Tragedy and Valor of Afghan, Iskon, Moscow 1995, Appendix 8, Translated by Svetlana Savranskaya , Document 21. CC CPSU Letter on Afghanistan, May 10, 1988.

4- Dmitry Timofeevich yazov : Moscow , USS Rministry Of Defense.

5 - The Economic Impact Of Soviet Involvement In Afghanistan (U) : Department Of Defence Intelligence Document, April . 1983 .

6 - This is a repository copy of Spooks, Tribes, and Holy Men: The Central Intelligence Agency and the Soviet Invasion of Afghanistan : University Of Ieeds, Https : //Eprints. Whit Rose .Ac.Uk

7 - US National Committee for Human Rights In Afghanistan , Russia's Barbarism In Afghanistan , Vol. 11 , April 1985,

(27) Dmitry Timofeevich yazov : Moscow , USS Rministry Of Defense, p.p. 1-2. 
8 - US House Of Congress : Hearing Before The Commission On Security And Cooperation In Europe, Soviet Violations of The Helsinki Accords In Afghanistan, 1985 .

\section{ثانيًا الرسائل الأجنبية}

1- Elliott Newton : Captivity and Conversion : AN IN

- Depth Study Of Soviet Pows In Afghanistan Submitted to the faculty of the University Graduate School in partial fulfillment of the requirements for the degree Master of Arts in the Department of Central Eurasian Studies, Indiana University August 2015 .

ثالثًا الدوريات

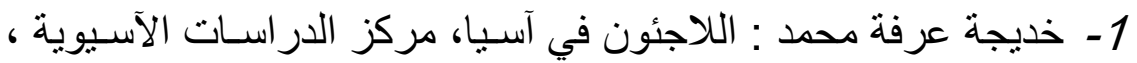

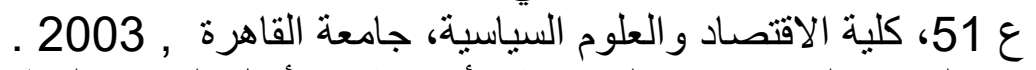

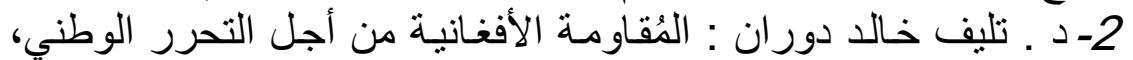

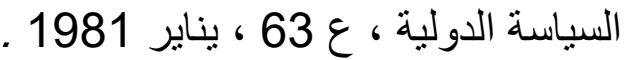

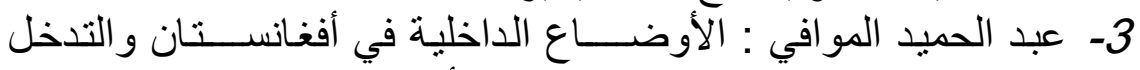

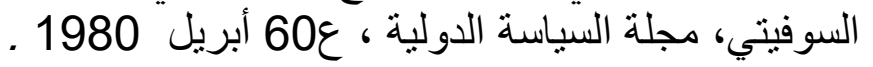

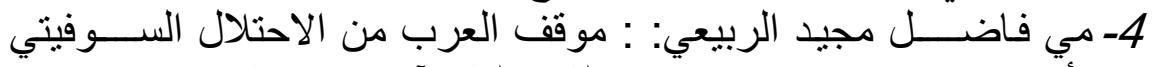

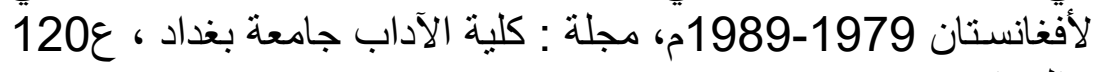

$$
\begin{aligned}
& \text {. } \\
& \text { رابعًا : الكتب العربية والمعرية : }
\end{aligned}
$$

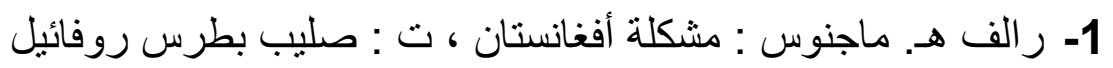

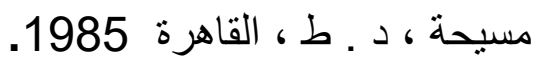

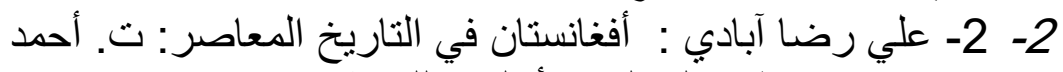

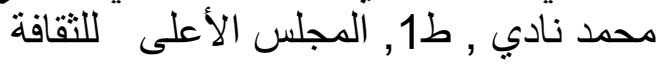

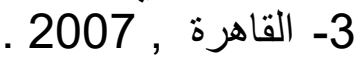

4- محمد عبد القادر أحمد : المسلمون في أفغانستان , ط .1 , مكتبة النهضة المصرية , القاهرة , 1984 
5- محمود شاكر : التاريخ المعاصر ، إيران- و أفغانستان ، ط.1 1995 , المكتب , الإنب

الإسلامي , بيروت , 1995 .

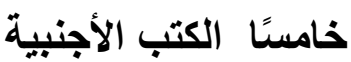

1- Asger Christensen: Aiding Afghanistan, The Back Ground And Prospects For Reconstruction In A Fragmented Society, Nordic Institute Of Asian Studies (N.I.A.S),1995 .

2-- Amnesty International : Democratic Republic Of Afghanistan, Background Briefing On Amnesty Internationals Concerns, November, 1983.

4- Antonio Haman : Pakistan After Zyaa , Asia Publishing House , London, 1988 .

5-- Alexiev Alexander : Inside The Soviet Army In Afghanistan, The RAND Corporation 1988.

7- Bruce Amstutz : Afghanistan The First Five Years Of Soviet Occupation National Defence University Washington, D. C. 20319- 6000, 1980 .

8--Christinlamb: waiting for Allah Pakistan's Struggle For Democracy Tallish, Oxford University, London, 1991.

9-Remote assessments of the archaeological heritage .9 Emily Hammer situation in Afghanistan , Afghanistan Cultural heritage Satellite imagery Archaeology Spatial analysis , 2017 . , Augus Available online at Science Direct www.sciencedirect.com

10 - Georgy M. Kornienko : The Cold War, When And Why The Decision To Send Troops To Afghanistan, Testimony Of Aparticipant, Moscow, Mezhdun Arodnye Otno Sheniya, 1994 . 
11- Rubin , B . R : Human Rights In Afghanistan In : $R$ . Klass (E.D) Afghanistan The Great Game Rivited New York, 1987 .

12-Van Royen .R : Repatriation Of Afghan Refugees, AUNHCR , Perspective In Afghanistan -Looking Into The Future Institute Of Strategic Studies, Islam Abad, 1990 .

$$
\text { سادسًا الصحف العربية }
$$

1- صحيفة الأهرام: 15 يناير 1980 ـ

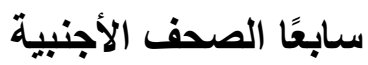

1 - Pravda : Corres Pondent I. Sh Chedrov's Letter To TheCCCPSU On The Situation In Afghanistan, November 12, 1981. 


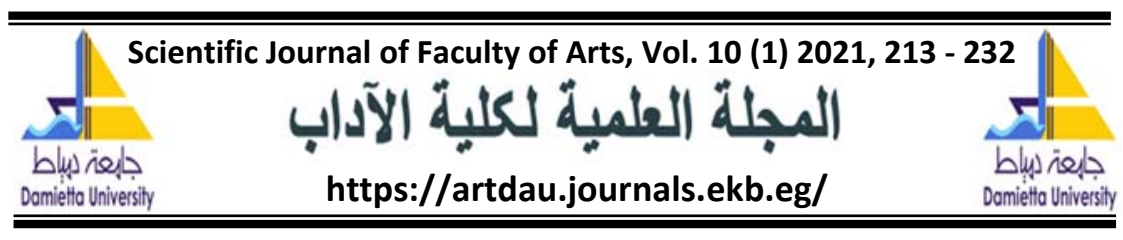

\section{The Soviet Invasion of Afghanistan 1979 - 1989}

Mayada Abdullah Muhammed Abdullah El-Helw

PhD. student, History Depart., Faculty of Arts, Damietta University.

$\frac{\text { Abstract }}{\text { The Soviet Invasion of Afghanistan in 1979-1989 complete }}$ the period of the Cold War and the ongoing international conflict between the Eastern Bloc and the Western Bloc that led to develop the manufacture of nuclear weapons and seizing oil extraction areas and energy sources in the Middle East.

The Soviet Union occupied Afghanistan in 1979 to ensure the safety of its southern borders with the republics of Turkmenistan, Uzbekistan and Turkestan, and feared the dissemination of Islam that caused after the Iranian revolution's outbreak that of 1979 would spread from Afghanistan on to warm water in the Indian Ocean. The United States helped prolong the Soviet-Afghan conflict to eliminate the Soviet Union's international force by providing the Afghan resistance factions with the most advanced technology. The 1979 Soviet occupation of Afghanistan had a number of negative social, political, economic, and military repercussions on Afghan and Soviet society, including the dissolution of the Soviet Union in 1991.

\section{Keywords:}

The Soviet, Afghanistan

Article history:

Received 6 February 2021

Received in revised form 23 February 2021

Accepted 30 March 2021 